\title{
On the evolution of comparative advantage in matching models
}

\author{
Eric O’N. Fisher ${ }^{\mathrm{a}, \mathrm{b}, 1}$, Vikas Kakkar ${ }^{\mathrm{c}}$ \\ 'European University Institute, The Johns Hopkins University, USA \\ ${ }^{\mathrm{b}}$ The Ohio State University, Ohio, USA \\ ${ }^{\mathrm{c}}$ Department of Economics and Finance, City University of Hong Kong, 83 Tat Chee Avenue, \\ Kowloon, Hong Kong
}

\begin{abstract}
This paper examines whether comparative advantage is the long-run outcome of an evolutionary process in the open economy. It formalizes the notion that natural selection eliminates inefficient firms and thus leads to stable and perhaps efficient patterns of world trade. Instead of assuming the existence of a Walrasian auctioneer, we study two simple matching processes that coordinate trade between firms. Our central result is that specialization according to comparative advantage, with the larger country possibly incompletely specialized, is the unique evolutionarily stable state of the world economy.
\end{abstract}

Keywords: Comparative advantage; Matching; Evolutionarily stable equilibrium

The principle of survival of the fittest can be regarded as a vast generalization of Ricardian economics

John Maynard Keynęs 


\section{Introduction}

There is a story that makes the rounds among international economists. As a young Fellow at Harvard, Paul Samuelson was challenged by one of his colleagues - who later became a renowned physicist— to state "one idea in economics that is true and not trivial". Samuelson immediately replied, "The concept of comparative advantage". Some might argue that comparative advantage is to productive efficiency what the Pareto property is to distributive efficiency. Both are ineluctable elements of a price-taking equilibrium, and they serve to formalize the notion that the invisible hand tends to promote the social good. This paper asks the question: Does an analog of the invisible hand lead to production according to comparative advantage in an evolutionary model? Our simple conclusion is: Yes.

Alchian (1950) is credited with the first insight that economic phenomena could be modeled in an evolutionary framework. He argued intuitively that natural selection within markets shapes economic activity in the long run. The main contribution of our work is to formalize his insight in a model of international trade. We follow Ricardo (1817) and assume that countries face different constant opportunity costs. Instead of modeling firms as price takers, we consider two simple matching processes. A firm enjoys the gains from trade only if it is matched with one that has a different good, and the gains from trade are divided according to a simple trading convention. We ask whether the pattern of trade will converge to that predicted by comparative advantage.

There are two approaches to studying comparative advantage in a Ricardian framework. The first and usual one assumes a perfectly competitive world market in which domestic and foreign firms are price-takers. Building upon Gabszewicz and Vial (1972) and Cordella and Gabszewicz (1997) have recently proposed a second approach where markets are imperfectly competitive and firms choose quantities strategically. They show that in a wide class of Ricardian economies, the unique Nash equilibrium is autarky. Hence, production according to comparative disadvantage can easily emerge. When the number of players in each country is sufficiently large, an equilibrium with trade is possible, but the no-trade outcome persists. Still, Cordella and Gabszewicz always maintain the assumption of a Walrasian auctioneer who clears world markets ${ }^{3}$.

A competitive equilibrium ensures that all mutually beneficial trades actually do materialize. The mechanism studied by Cordella and Gabszewicz generates another extreme outcome, in which it is possible that no mutually beneficial trade is realized. Perhaps a model that avoids these two extremes might better approximate a complex modern economy. International markets are not frictionless, so some mutually beneficial trades may not occur. And even casual

\footnotetext{
${ }^{3}$ So do the noteworthy contributions of Fisher (1985) and Ruffin (2001), both of which are imperfectly competitive models with Ricardian frameworks.
} 
observation contradicts the prediction that no mutually beneficial trade ever takes place $^{4}$. This paper proposes an alternative approach, combining elements of perfect competition and strategic behavior in an evolutionary framework. We drop the ideal of a Walrasian auctioneer and assume instead that a simple matching process coordinates trade. If a producer is lucky enough to meet someonedomestic or foreign-who has produced a different good, then a mutually beneficial trade occurs.

Here are the details of the production and matching processes. Producers anywhere in the world can produce one of two goods. Before the match, a firm produces a good. If two matched firms have the same good, then there are no gains from trade and each firm consumes what it brought to the match. It is perhaps useful to think of this as a sterile meeting, since it captures the idea that a mutually beneficial trade is not realized. Otherwise, there is a fertile meeting that may be viewed as a temporary bilateral monopoly. The division of the gains from trade then depends on the bargaining powers of the two firms, and we assume that they share the social surplus equally ${ }^{5}$. This rule corresponds to the Nash bargaining solution, since the threat point of either agent is to consume his own output, yielding a utility level of zero for our specification of preferences.

We study two matching processes: one where a firm can meet anyone and another where a firm automatically meets a foreign counterpart. The first mechanism is general in that it allows both international and intra-national matches, with the probability of each type of match being determined by the relative sizes of the countries. Using the assumption of identical Cobb-Douglas preferences, we show that the unique Nash equilibrium is evolutionarily stable and that production follows comparative advantage. A small country specializes in the good in which it has a comparative advantage, and a large country is incompletely specialized. Our analysis suggests that the assumption of "sufficient competitive forces" (Cordella and Gabszewicz, 1997, p. 346) is not necessary for the world economy to display convergence to an equilibrium where production follows comparative advantage. Moreover, in an evolutionary framework, we make no explicit assumptions about rationality, perfect information, or common knowledge. Thus production according to comparative advantage is a deep outcome, even in a matching model with explicit frictions that prevent market forces from working their ineluctable magic.

It is natural to ask whether one can rationalize within our model the kind of no-trade equilibrium that Cordella and Gabszewicz highlighted. Surprisingly, one

\footnotetext{
${ }^{4}$ The empirical evidence on the Ricardian hypothesis suggests that the truth lies between these extremes. For instance, Golub and Hsieh (2000) find that a large proportion of the sectoral variation of trade remains unexplained, although labor productivity differences have the correct sign and are statistically significant.

${ }^{5}$ Allowing for different bargaining powers or even using the Walrasian allocations does not change our qualitative results.
} 
can. Our second matching process imposes that only international matches can occur. In this case, the world economy has two Nash equilibria, both of which are evolutionarily stable. One corresponds to complete specialization according to comparative advantage, while the other entails the opposite pattern. In Cordella and Gabszewicz, the "bad equilibrium" arises because the representative agent has extreme preferences, deriving utility largely from the good in which it has comparative disadvantage. In our model, home and foreign firms have identical preferences and both goods are desirable. However, in our second matching process, the "bad" outcome arises because foreigners are increasingly specialized in the "wrong" good. No firm producing the "right" good will get a high payoff because it has only a small chance of entering into a fertile match with its foreign counterpart. Thus being locked into the wrong pattern of production can be mutually reinforcing, if there is a strong restriction in the matching process.

Since the evolutionary model is dynamic, it is possible to identify initial conditions under which the world economy will converge to the "good" or "bad" equilibrium. In particular, we show that if the initial conditions correspond to the evolutionarily stable strategy for two hitherto closed economies, then the world economy converges monotonically to the "good" equilibrium. Following Foster and Young (1990), we also examine the consequences of small random shocks to the pattern of production in each economy. Imposing an explicit process for random mutations and using simulations, we show that the equilibrium with comparative advantage is stochastically stable. Thus, even if the world economy is stuck in the "wrong" equilibrium, in the very long run, the random mutations will allow it to escape to the "good" equilibrium with comparative advantage.

Specialization according to comparative advantage turns out to be a robust prediction of the evolutionary models we examine. We note in passing that this result has implications beyond the arena of international trade. In particular, the vast literature on search and matching has also studied deviations from frictionless Arrow-Debreu economies. Two seminal papers are Diamond (1982) and Kiyotaki and Wright (1989). Their common point of departure is the assumption that agents cannot consume their own goods, and therefore, need to trade. This postulate reflects the "advantage of specialized production and trade over self-sufficiency" (Diamond, 1982, p. 883). Diamond examines the implications of this idea for a theory of unemployment, whilst Kiyotaki and Wright use it to develop a theory of money. One can view our results as a theoretical underpinning for this crucial and widespread assumption.

The rest of the paper is organized as follows. The next section provides an overview of the concepts and methods of evolutionary game theory that are used in this paper. In the third section we sketch the model for the closed economy and describe static and dynamic aspects of its equilibrium. The fourth section studies the open economy model with both international and intra-national matches. The fifth section studies the open economy under the restricted matching mechanism and shows that multiple equilibria are possible. The sixth section imposes a 
specific process for random mutations and discusses properties of the stochastically stable set; several illuminating simulations are analyzed. The seventh section presents some brief conclusions and suggestions for future research.

\section{A thumbnail sketch of evolutionary game theory for the international economist}

Applying evolutionary game theory to comparative advantage is a surprisingly open area of research. Thus there is very little literature upon which we build directly. The only application of evolutionary game theory in international economics is by Friedman and Fung (1996), but they study the organization of firms, not the evolution of comparative advantage. On the other hand, there is a vast literature on international trade under less than perfect competition.

The literature on evolutionary game theory has grown rapidly in the last decade. An important early article is by Friedman $(1991,1998)$ summarizes the same ideas in a technically less demanding fashion. There are now three excellent books summarizing this body of research: Weibull (1995), Samuelson (1997) and Vega-Redondo (1996). Using dynamics that stress imitation and mutation, VegaRedondo (1997) studies the evolution of price-taking behavior in partial equilibrium. He uses a model with finitely many firms producing a homogenous good. Such an analysis is of limited interest for international economists because there is no reason for trade.

The fundamental concept in evolutionary game theory is the notion of an evolutionarily stable strategy. Consider a large population of identical agents. A biologist would call this a monomorphic population, and an international economist might think of this as a closed economy. These agents meet often in random pair-wise matches. Each agent is completely described by its list of behaviors (pure strategies) and by a function describing the fitness (payoff) that arises when any one behavior meets another. An evolutionarily stable strategy is a symmetric equilibrium that satisfies two properties. First, each strategy must be a best response to itself. Second, if a sufficiently small fraction of the population adopts another strategy, then agents who stick with the original one should earn a higher payoff than those who decided to switch. Thus a strict Nash equilibrium is an evolutionarily stable strategy because it is a best response to itself and to other mixed strategies that are close enough to it. If the equilibrium is a mixture of several pure strategies, then there are several best responses to it $^{6}$. Now one has to check the second condition; this property is summarized by the idea that the

\footnotetext{
${ }^{6}$ Nash himself first proposed the idea that a mixed strategy could be thought of as a distribution of genes, but the formal definition of an evolutionarily stable strategy was not proposed until two decades later.
} 
original (equilibrium) strategy has a higher degree of fitness against the mutants than the mutants have against themselves.

For an international economist, a model of a monomorphic population is less than half the picture. Now consider a bimorphic population, one with two types of agents; a moment's reflection shows that the genetic characteristics of foxes will certainly influence natural selection in the population of rabbits (and vice versa). The study of bimorphic populations is natural for an international economist, since the characteristics of foreign firms influence the profitability of domestic producers. Now the definition of an evolutionarily stable strategy is not so straightforward. We follow the usual convention and analyze Nash equilibria that are resistant to invasion by a small share of mutants within one population at a time. Thus a rabbit gene that "causes" fast running is an evolutionarily stable strategy if a sufficiently small share of mutant slow bunnies does not fare well against the current population of foxes.

In our evolutionary model, there are two behaviors in the population of domestic firms: producing the first or second good. We show that the matching process in the closed economy gives rise to a Hawk-Dove game. A population full of hawks-firms with a predisposition for producing the first good-is not going to have a high level of average fitness. Likewise, a population full of doves-firms producing only the second good-will run into similar difficulties. As we shall see below, the unique evolutionarily stable strategy for the closed economy consists of a mix of hawks and doves. If preferences satisfy some simple properties and the gains from trade are divided according Nash bargaining, then this mix induces exactly the shares of firms in each sector that maximizes expected social surplus. Thus our matching process has some attractive properties for the closed economy.

When an economy opens for international trade, something different occurs. Now the world economy consists literally of two different species: homeboys and foreign animals. Homeboys and foreign animals face different technological tradeoffs. At first, both homeboys and foreign animals have distributions of behaviors, with some producing the first good and others the second. Fitness is determined by a continual series of matches between animals on the world stage ${ }^{7}$. In our general model, homeboys can meet anyone, including their own ilk. In this model, comparative advantage arises naturally, and it is the unique evolutionarily stable state. In the restricted model, homeboys can only meet foreign animals. Now there are two evolutionarily stable strategies: one in which all the homeboys produce the first good and all the foreign animals produce the second good and the other with the opposite pattern of trade.

Why does the situation with restricted matches give rise to such a different outcome? Selten (1980) has the right intuition; since homeboys always meet foreign animals, no distribution of behaviors on the interior of the simplex is

\footnotetext{
${ }^{7}$ We hope that our admittedly colorful language does not distract the reader unduly. It does give a new meaning to the term "international competitiveness".
} 
stable. If two strategies have the same payoffs, then nothing punishes genetic drift. On the other hand, in the general model, if a small share of mutants enters the world economy, the corresponding behavior will meet itself with strictly positive probability and the expected fitness of the entrants drops. Thus the original distribution of strategies following comparative advantage is stable.

A big advantage of evolutionary game theory is that there is a natural link with a dynamical system whose state is the distribution of strategies in the population. There are different rules for describing the dynamics of the system, but the most common is perhaps the replicator dynamic. This rule states that a strategy's relative share in the population increases in proportion to how much its fitness exceeds the average level of fitness. It is perhaps the simplest way to capture Darwin's deep insight. While the assumption of replicator dynamics is natural for biological models, it requires some justification in an economic model. There are at least four reasons for choosing this rule. First, it is computationally simple and easy to exposit. Second, it allows for some inertia in the model because the distribution of strategies changes gradually rather than abruptly (Friedman, 1998). Third, if imitation is the economic analog of genetic transmission and an important component of how agents learn, then the replicator dynamics is likely to provide a good approximation to the process of strategy selection (Samuelson, 1997, p. 63). Finally, under the replicator dynamics, an evolutionarily stable strategy is also an evolutionary equilibrium, in the sense that no small-scale invasion by equilibrium entrants can push the world economy away from this pattern of production.

We do not explicitly model the learning behavior of firms, but simply note that a variety of imitation-driven models give rise to the dynamics assumed here, at least approximately. For instance, suppose that firms are infinitely lived and boundedly rational. After each period, a firm reviews its strategy by sampling another firm at random. The reviewing firm observes its payoff and that of the sampled firm with some noise. If the observed difference is positive, the reviewing firm switches to the sampled firm's strategy; otherwise it continues with the old strategy. If the noise process is uniformly distributed, the imitation dynamics of this model are simply a rescaling of the replicator dynamics by a positive constant ${ }^{8}$. Given that there is no consensus yet on the most reasonable general approach to modeling learning by economic agents, using the replicator dynamics seems appropriate for our purposes. We study some dynamic properties of the closed and open economies at several points in the analysis below.

Imposing an explicit process for random mutations and using simulations, we show that the equilibrium with comparative advantage is stochastically stable. An

\footnotetext{
${ }^{8}$ For more general noise processes, the imitative dynamics are payoff-monotonic and have the same set of stationary states as the replicator dynamics. Moreover, in the neighborhood of a stationary state, a linear approximation yields the replicator dynamics rescaled by a positive constant. See Weibull (1995) (pp. 157-158) for details and other examples of models that yield dynamics similar to the replicator dynamics.
} 
equilibrium of a biological system - thought of as a population state-is stochastically stable if, as the probability of mutations becomes asymptotically small, the population spends almost all its time in a neighborhood of this state. Thus, even if the world economy is initially stuck in the "wrong" equilibrium, in the (very) long run, random mutations will allow it to escape. When there is strong comparative advantage, the expected waiting time for the "right" equilibrium will be short enough, but for plausible calibrations with fairly large mutations, it may take five centuries of monthly trading for the right configuration of mutations to arise!

\section{The model in a closed economy}

The closed economy consists of a continuum of identical agents. Each agent is both a consumer and producer. There are two commodities in the world economy, and the representative agent's preferences are summarized by the log-linear utility function $u: \mathfrak{R}_{+}^{2} \rightarrow \mathfrak{R}$ whose rule is $u(x)=\left(x_{1}\right)^{\alpha}\left(x_{2}\right)^{1-\alpha}$. Each agent is endowed with one unit of time, and the production process is indivisible, so that an agent can produce either good 1 or good 2, but not both. Thus each agent has the production set $Y=\left\{\left(1 / a_{1}, 0\right)^{\mathrm{T}},\left(0,1 / a_{2}\right)^{\mathrm{T}}\right\} \subset \mathfrak{R}_{+}^{2}$ where $a=\left(a_{1}, a_{2}\right)^{\mathrm{T}}$ is the vector of labor coefficients. Since this set is not convex, each agent is forced to trade if it wants a mix of the two goods. In each period, an agent produces one of the goods without knowing what the rest of the population has chosen. Even though each agent's production set is not convex, the production possibility frontier for the entire economy is. In essence, nature can choose any fraction of a large population of agents to produce either good, and she faces the typical constant opportunity cost that characterizes the essence of a Ricardian technology ${ }^{9}$. When a random match occurs, the surplus is split according to simple Nash bargaining. Let $u_{\mathrm{h}}(1 / 2) u\left(1 / a_{1}, 1 / a_{2}\right)$; we can now summarize this aspect of the model succinctly.

Assumption 1. The (row player's) payoffs in the closed economy are

$$
A=\left[\begin{array}{ll}
0 & u_{\mathrm{h}} \\
u_{\mathrm{h}} & 0
\end{array}\right] .
$$

The upper left element is the row player's payoff if he produces the first good and has a sterile match; the upper right element is his payoff if he meets a column player who has produced the second good and thus has a fertile match. The payoffs correspond to Nash bargaining solution in each of the four possible

\footnotetext{
${ }^{9}$ Alternatively, one can also view each individual agent as "choosing" a possibly mixed strategy $r=\left(r_{1}, 1-r_{1}\right), 0 \leq r_{1} \leq 1$, where $r_{1}$ is the probability of producing the first good. Allowing for mixed strategies renders each agent's strategy choice set convex, and aggregating over all agents and appealing to the law of large numbers results in the usual linear Ricardian production possibilities frontier for the economy.
} 
outcomes. It is obvious that a population of agents producing only the first good will not fare well. Random matching introduces an explicit friction into this economy, and an important element of the theoretical analysis is to show that pattern of trade largely follows comparative advantage in spite of this strong trading imperfection.

Let $\Delta=\left\{s \in \mathfrak{R}_{+}^{2} \mid s_{1}+s_{2}=1\right\}$ be the relevant simplex. The state of the system is an element $s \in \Delta$ describing the distribution of the population producing each good. A strategy for a home or foreign firm is a vector $r=\left(r_{1}, r_{2}\right)^{\mathrm{T}} \in \Delta$ with the interpretation that the firm produces good 1 with probability $r_{1}$ and good 2 with probability $r_{2}$. Then the fitness of a firm that plays strategy $r=\left(r_{1}, r_{2}\right)^{\mathrm{T}}$ when the state is $s \in \Delta$ is $f(r, s)=r^{\mathrm{T}} A s$. Some simple algebra shows that

$$
f(r, s)=\left(r_{1} s_{2}+r_{2} s_{1}\right) u_{\mathrm{h}}
$$

We can now state our first result.

Proposition 3.1. The model in the closed economy is a Hawk-Dove game. Its unique evolutionarily stable strategy is $\hat{s}=(1 / 2,1 / 2)^{\mathrm{T}}$. Moreover, this strategy maximizes social surplus, given the matching technology.

Proof. The model is a Hawk-Dove game because the diagonal elements of the payoff matrix are zero and its off-diagonal elements are positive. Since the best response to state $s \in \Delta$ is $r=(1,0)^{\mathrm{T}}$ if $s_{2}>1 / 2$ and $r=(0,1)^{\mathrm{T}}$ if $s_{1}>1 / 2$, it is easy to see that the unique Nash equilibrium is $\hat{s}=(1 / 2,1 / 2)^{\mathrm{T}}$. Since this is not a strict Nash equilibrium, we need to show that for any $r \neq \hat{s}$ there exists $\varepsilon>0$ such that $f\left(\hat{s}, s_{\varepsilon}\right)>f\left(r, s_{\varepsilon}\right)$, where $s_{\varepsilon}=(1-\varepsilon) \hat{s}+\varepsilon r$. The fitness of the original population is $f\left(\hat{s}, s_{\varepsilon}\right)=(1-\varepsilon) u_{\mathrm{h}} / 2+\varepsilon\left(r_{1}+r_{2}\right) u_{\mathrm{h}} / 2$ and that of the mutants is

$$
f\left(r, s_{\varepsilon}\right)=\frac{(1-\varepsilon)\left(r_{1}+r_{2}\right) u_{\mathrm{h}}}{2}+\varepsilon\left(r_{1} r_{2}+r_{2} r_{1}\right) u_{\mathrm{h}} .
$$

Since $r_{1}+r_{2}=1$,

$$
\left.\left.f\left(\frac{1}{2}, \frac{1}{2}\right)^{\mathrm{T}}, s_{\varepsilon}\right)-f\left(\left(r_{1}, r_{2}\right)^{\mathrm{T}}, s_{\varepsilon}\right)\right)=\varepsilon\left(\frac{1}{2}-2 r_{1} r_{2}\right) u_{\mathrm{h}}>0 .
$$

This inequality is true because $\left(1 / 2-2 r_{1} r_{2}\right) \geq 0$, with equality only if $1 / 2=r_{1}=$ $r_{2}$. Hence, for any $\varepsilon>0, f\left(\hat{s}, s_{\varepsilon}\right)>f\left(r, s_{\varepsilon}\right)$ and the population state $\hat{s}=(1 / 2,1 / 2)^{\mathrm{T}}$ is an evolutionarily stable strategy.

The strategy $\hat{s}=(1 / 2,1 / 2)^{\mathrm{T}}$ maximizes expected social surplus because it maximizes the chance of fertile matches.

The fitness of the population of domestic firms is $f(\hat{s}, \hat{s})=u_{\mathrm{h}} / 2$. If each firm could be assured of meeting an appropriate counterpart with the opposite good, then the average welfare of the population would be $u_{\mathrm{h}}$. But half that surplus is 
lost because the random matching process cannot guarantee that every match is fertile. Still, it is noteworthy that the "correct" shares of firms go into the each industry. These shares are correct since the Nash bargaining rule splits the surplus from a fertile match equally.

Now let $z \in \Delta$ be any arbitrary population state, with the usual interpretation that the fraction $0 \leq z_{i} \leq 1$ of the population is of the $i$-th type. The replicator dynamics are described by

$$
\dot{z}_{i}=\left(e^{i}-z\right)^{\mathrm{T}}(A z) z_{i}
$$

where $e^{i}$ is the vector with unity in the $i$-th position and zero elsewhere. Some simple calculations show that $\dot{z}_{1}=\left(1-2 z_{1}\right) z_{1} z_{2} u_{\mathrm{h}}$ and $\dot{z}_{2}=-\dot{z}_{1}$. Convergence to the evolutionarily stable strategy is quick if the average level of productivity is high.

\section{A general matching model for the open economy}

This section extends the model to allow for international matches. Now trade can take place both within an economy and between economies, since a home firm can be matched with any firm in the world. Let $\mu$ denote the relative size of the home country and $1-\mu$ that of foreign country. Firms in this world population are randomly matched, so for any firm-home or foreign - the probability of being matched with a home firm is simply $\mu$. We summarize the matching process:

Assumption 2. The probability of meeting a domestic (foreign) firm is equal to the share of domestic (foreign) firms in the world population.

Now consider the open economy modeled as a bimorphic population of home and foreign firms. In order to keep the equilibrium as simple as possible, we assume that both countries have identical preferences again represented by $u(x)=$ $\left(x_{1}\right)^{\alpha}\left(x_{2}\right)^{1-\alpha}$. The production set for the foreign country is given by $Y^{*}=\left\{\left(1 / a_{1}^{*}\right.\right.$, $\left.0)^{\mathrm{T}},\left(0,1 / a_{2}^{*}\right)^{\mathrm{T}}\right\}$ where $a^{*}=\left(a_{1}^{*}, a_{2}^{*}\right)^{\mathrm{T}}$ is the vector of labor coefficients for the foreign country. With only slight loss of generality, we assume that $a_{1} / a_{1}^{*}<a_{2} / a_{2}^{*}$, namely that the home country has strict comparative advantage in good 1 .

In the event that a home firm is matched with another home firm, the same matrix $A$ describes its payoffs. Let $u_{\mathrm{f}}=(1 / 2) u\left(1 / a_{1}^{*}, 1 / a_{2}^{*}\right)$. The following is the analog of Assumption 1.

Assumption 1*. The foreign (row player's) payoffs for intra-national foreign matches are

$$
A^{*}=\left[\begin{array}{ll}
0 & u_{\mathrm{f}} \\
u_{\mathrm{f}} & 0
\end{array}\right] .
$$


Consider any firm that has been matched with a counterpart from abroad, and let $\bar{u}=(1 / 2) u\left(1 / a_{1}, 1 / a_{2}^{*}\right)$ and $\bar{u}=(1 / 2) u\left(1 / a_{1}^{*}, 1 / a_{2}\right)$. Note that the assumption of identical Cobb-Douglas preferences implies that $u_{\mathrm{h}} u_{\mathrm{f}}=\bar{u} \bar{u}$, a fact that will be very useful in the proofs below. We summarize our assumptions for international matches:

Assumption 3. The domestic (row player's) payoffs in an international match are

$$
B=\left[\begin{array}{ll}
0 & \bar{u} \\
\underline{u} & 0
\end{array}\right] \text {. }
$$

Also, $\bar{u}>\underline{u}$, and $u_{\mathrm{h}} u_{\mathrm{f}}=\bar{u} \bar{u}$.

The diagonal elements of $B$ correspond to the payoffs from the sterile encounters. In a fertile encounter, we assume again that the resulting social surplus is divided equally. The element $\bar{u}$ is the payoff when a match follows production according to comparative advantage, and $\underline{u}$ is the payoff for the opposite configuration of goods. Since preferences and the simple rule for dividing the gains from trade might confound comparative advantage we postulate further that $\bar{u}>\underline{u}$. A sufficient condition is $\alpha \geq 1 / 2^{10}$. Since there is no price mechanism guiding production in this model, it is important that a fertile match according to comparative advantage have a relatively high payoff.

These matrices enable us to define the fitness functions for the representative agent in the home or foreign country. Recall that $\Delta$ is the one-dimensional simplex; now the state space $S=\Delta \times \Delta$ gives a complete description of the population shares of domestic and foreign firms producing the two different goods. A generic element is $s=\left(z, z^{*}\right) \in S$, where $z=\left(z_{1}, z_{2}\right)^{\mathrm{T}}$ is the vector of population shares of home firms in the two sectors and $z^{*}=\left(z_{1}^{*}, z_{2}^{*}\right)^{\mathrm{T}}$ is analogous for the shares of foreign firms.

The fitness of a domestic firm that plays strategy $r=\left(r_{1}, r_{2}\right)^{\mathrm{T}}$, when the state is $s \in S$, is $f(r, s)=\mu r^{\mathrm{T}} A z+(1-\mu) r^{\mathrm{T}} B z^{*}$. Some simple algebra shows that

$$
f(r, s)=\left[\mu z_{2} u_{\mathrm{h}}+(1-\mu) z_{2}^{*} \bar{u}\right] r_{1}+\left[\mu z_{1} u_{\mathrm{h}}+(1-\mu) z_{1}^{*} \underline{u}\right] r_{2} .
$$

The expression in the first square bracket in (1) is the expected payoff from producing good 1 and meeting either a home firm or a foreign firm and then having a fertile match, and that in the second square bracket is the expected payoff from producing good 2. It is now easy to see that the fitness of a foreign firm is $f^{*}(r, s)=\mu r^{\mathrm{T}} B^{\mathrm{T}} z+(1-\mu) r^{\mathrm{T}} A^{*} z^{*}$, or

$$
f^{*}(r, s)=\left[\mu z_{2} \underline{u}+(1-\mu) z_{2}^{*} u_{\mathrm{f}}\right] r_{1}+\left[\mu z_{1} \bar{u}+(1-\mu) z_{1}^{*} u_{\mathrm{f}}\right] r_{2} .
$$

Eq. $(1 *)$ is of course exactly analogous to (1).

\footnotetext{
${ }^{10}$ The exact condition is $\alpha \geq \ln \left(a_{2}^{*} / a_{2}\right) /\left\{\ln \left(a_{1}^{*} / a_{1}\right)+\ln \left(a_{2}^{*} / a_{2}\right)\right\}$. Since the home country has comparative advantage in the first good, the right side of this inequality is not greater than $1 / 2$.
} 
A state $s=\left(z, z^{*}\right) \in S$ is a Nash equilibrium for the evolutionary game defined by the fitness functions $f\left(.\right.$, .) and $f^{*}\left(.\right.$, .) if $f(z, s) \geq f(r, s)$ and $f^{*}\left(z^{*}, s\right) \geq f^{*}(r, s)$ for all $r \in \Delta$. An evolutionarily stable strategy is a Nash equilibrium $s=\left(z, z^{*}\right) \in S$ such that the following two conditions are satisfied. First, for domestic firms it must be the case that: either (i) $f(z, s)>f(r, s)$ for all $r \neq z \in \Delta$; or (ii) if $f(z ; s)=f(r$; $s$ ) for some $r \in \Delta$, then there exists $\varepsilon>0$ such that $f\left(z, s_{\varepsilon}\right)>f\left(r, s_{\varepsilon}\right)$, where $s_{\varepsilon}=(1-\varepsilon) s+\varepsilon\left(r, z^{*}\right)$. Second, for foreign firms it must be true that: either (i) $f^{*}\left(z^{*}, s\right)>f^{*}(r, s)$ for all $r \neq z^{*} \in \Delta$; or (ii) if $f^{*}\left(z^{*}, s\right)=f^{*}(r, s)$ for some $r \in \Delta$, then there exists $\varepsilon>0$ such that $f^{*}\left(z^{*}, s_{\varepsilon}\right)>f^{*}\left(r, s_{\varepsilon}\right)$, where now $s_{\varepsilon}=(1-\varepsilon) s+\varepsilon(z$, $r)$.

We can now begin the description of the evolutionarily stable strategies. Notice first that neither $\left((1,0)^{\mathrm{T}},(1,0)^{\mathrm{T}}\right) \in S$ nor $\left((0,1)^{\mathrm{T}},(0,1)^{\mathrm{T}}\right) \in S$ is a Nash equilibrium, since it would never be optimal to enter into a sterile match with certainty. Could it be a Nash equilibrium to produce according to comparative disadvantage? We will demonstrate in four steps that this cannot happen. First, we will show that it is not a Nash equilibrium for both countries to specialize according to comparative disadvantage. Second, we will demonstrate that it is not a Nash equilibrium for either country to specialize according to comparative disadvantage, even if its trading partner is incompletely specialized. Third, we will show that it is not a Nash equilibrium for both countries to be incompletely specialized. Finally, we will show that specialization according to comparative advantage is the unique evolutionarily stable strategy.

Proposition 4.1. Complete specialization according to comparative disadvantage is not an equilibrium.

Proof. See Appendix A.

The intuition behind Proposition 4.1 is that producing according to complete comparative disadvantage is so unfit that either a home firm or a foreign firm (or both) would find it preferable to switch to the sector in which it has a comparative advantage, even if it only has fertile matches with firms in its own country.

We still need to check whether one country can specialize in the good in which it has a comparative disadvantage while the other country is incompletely specialized. We now state.

Proposition 4.2. No Nash equilibrium is such that a country is completely specialized in the good in which it has a comparative disadvantage.

Proof. See Appendix A.

The intuition behind Proposition 4.2 is that specializing according to comparative 
disadvantage gives such a low level of fitness that switching goods is an improvement, even if one only meets a few foreign firms.

Since an evolutionarily stable strategy is necessarily a Nash equilibrium, the following obtains.

Corollary 4.3. The pattern of production in which both countries follow comparative disadvantage is not an evolutionarily stable strategy.

The following narrows the set of equilibria further.

Proposition 4.4. There is no Nash equilibrium in which both countries are incompletely specialized.

Proof. See Appendix A.

We still have to show that a Nash equilibrium in which production follows comparative advantage is indeed evolutionarily stable. We do this by assuming that the firms' choices are best responses and checking whether they satisfy the extra condition that characterizes evolutionary stability.

Proposition 4.5. The pattern of production according to comparative advantage is evolutionarily stable.

Proof. See Appendix A.

We can now state the central contribution of our research

Theorem 4.6. Under Assumptions 1, 1*, 2 and 3, the evolutionarily stable strategies are unique. If the relative size parameter $\mu<u_{f} /\left(u_{f}+\bar{u}\right)$, then the home country is completely specialized according to comparative advantage and the foreign country is incompletely specialized. If $u_{f} /\left(u_{f}+\bar{u}\right) \leq \mu \leq \bar{u} /\left(u_{h}+\bar{u}\right)$, then both countries are completely specialized according to comparative advantage. If $\bar{u} /\left(u_{h}+\bar{u}\right)<\mu$, the foreign country is completely specialized according to comparative advantage and the home country is incompletely specialized.

Proof. If the foreign country is incompletely specialized, then a foreign firm must be indifferent between entering the first or second sector. Hence, $(1-\mu) z_{2}^{*} u_{\mathrm{f}}=$ $\mu \bar{u}+(1-\mu) z_{1}^{*} u_{\mathrm{f}}$. It is easy to check that the solution to this equation has $0<z_{1}^{*}<1 / 2$ if and only if $0<\mu<u_{\mathrm{f}} /\left(u_{\mathrm{f}}+\bar{u}\right)$. If this condition is true, then Propositions 4.2 and 4.4 show that the home country must be specialized in the first sector.

If the home country is incompletely specialized, then a home firm must be indifferent between entering the first or second sector. Hence, $(1-\mu) \bar{u}+\mu z_{2} u_{\mathrm{h}}=$ 
$\mu z_{1} u_{\mathrm{h}}$. The solution to this equation has $1 / 2<z_{1}<1$ if and only if $\bar{u} /\left(u_{\mathrm{h}}+\bar{u}\right)<$ $\mu<1$. If this condition is true, then Propositions 4.2 and 4.4 show that the foreign country must be completely specialized in the second sector.

In both these cases, the uniqueness of the Nash equilibrium follows from the linearity of the fitness functions $f(.,$.$) and f^{*}(.,$.$) in the state variables z$ and $z^{*}$. If the home country is completely specialized, there is a unique distribution of firms that makes a foreign firm indifferent between producing the two goods. The same is true for the case when the foreign country is completely specialized.

If $u_{\mathrm{f}} /\left(u_{\mathrm{f}}+\bar{u}\right) \leq \mu \leq \bar{u} /\left(u_{\mathrm{h}}+\bar{u}\right)$, then neither country can be indifferent about which good it produces and thus both countries must be completely specialized. Proposition 4.2 shows that both countries must be completely specialized according to comparative advantage. Uniqueness of the Nash equilibrium is trivially implied here.

In each case, the uniqueness of the evolutionarily stable strategy follows from the uniqueness of the corresponding Nash equilibrium.

This theorem is the main contribution of our work. It shows that production according to comparative advantage arises naturally in a matching model in which the agents exhibit little (if any) rationality. Our model is so simple that there is no role for prices. Thus we have had to assume a match according to comparative advantage yields higher utility than one according to comparative disadvantage, but Assumption 3 is more stringent than necessary. In particular, it will always be the case that a (perhaps asymmetric) social convention could arise in which both foreign and domestic agents could divide the surplus from producing according to comparative advantage in a way that was Pareto superior to producing according to comparative disadvantage. This is true even if the agents have different preferences that need not be homothetic. It is likely that (asymmetric) versions of all the propositions in this section would also be true. We conjecture that production according to comparative advantage will arise in a more general model, but have made enough simplifying assumptions in this section so that the social convention based upon Nash bargaining gives us Theorem 4.6.

We also ought to make an important observation about the welfare effects of trade in this version of the model. Theorem 4.6 says nothing about the gains from trade; it is a description of the pattern of exports in a model with severe market frictions and a simple convention for dividing the gains inherent in a fertile match. It is easy to see that a country with a strong absolute advantage in both goods may well experience lower average utility from trade ${ }^{11}$; after all, Assumption 3 does not impose that $\bar{u}>u_{\mathrm{h}}$ or $\bar{u}>u_{\mathrm{f}}$, but only that $\bar{u}>\underline{u}$. We do not feel that this

\footnotetext{
${ }^{11}$ We thank Priya Ranjan, our discussant at the University of California at Santa Cruz's New Methods in International Economics Workshop, for making this point so clearly. We conjecture that a more sophisticated convention for dividing the gains from trade would guarantee not only that trade followed comparative advantage but also that it did not lower average welfare for either country.
} 
observation is a weakness of the model. Instead, it shows that even in a severely distorted world economy, the old magic of comparative advantage predicts the pattern of trade well.

How will the distribution of firms in the world economy evolve? Let $s=(z$, $\left.z^{*}\right) \in \Delta \times \Delta$ be the population state. Now the replicator dynamics for domestic firms in industry $i$ are:

$$
\dot{z}_{i}=\left[e^{i}-z\right]^{\mathrm{T}}\left[\mu A z+(1-\mu) B z^{*}\right] z_{i},
$$

where again $e^{i}$ is a vector with unity in the $i$-th position and zeros elsewhere. The analogous dynamic for foreign firms is:

$$
\dot{z}_{i}^{*}=\left[e^{i}-z^{*}\right]^{\mathrm{T}}\left[\mu B^{\mathrm{T}} z+(1-\mu) A^{*} z^{*}\right] z_{i}^{*} .
$$

This coupled system of differential equations describes the dynamics of the world economy.

Fig. 1 is worth a thousand words ${ }^{12}$. The locus $L^{\mathrm{h}}$ is the set of points in the state space such that the share of domestic firms in either industry is constant. Consider its leftmost point; the parameters are such that even if all the foreign firms are specialized in the first (and thus wrong) sector and about $20 \%$ of the home firms are producing that good, then a domestic firm is indifferent between either activity. Points below this locus will be such that a home firm finds the first activity relatively profitable and the share of domestic firms in the first (right) sector is increasing. The $L^{\mathrm{h}}$ locus slopes down because now decreased foreign competition is offset by increased local competition. Likewise, the locus $L^{\mathrm{f}}$ is the set of points

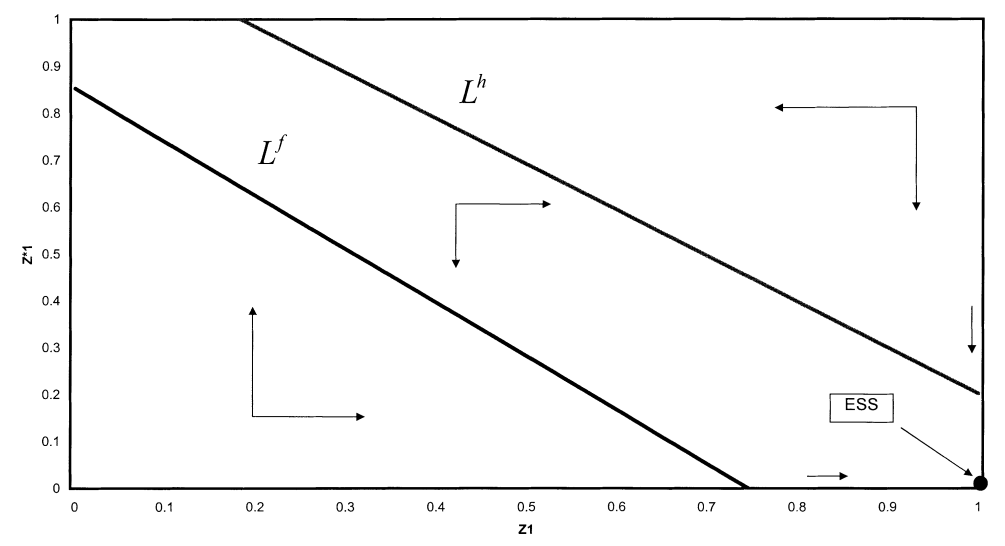

Fig. 1. Complete specialization phase diagram.

\footnotetext{
${ }^{12}$ In this case and all subsequent simulations, we set $a=(1,2)^{\mathrm{T}}, a^{*}=(2.5,1)^{\mathrm{T}}, \mu=0.5$, and $\alpha=0.5$. The home country has moderate comparative advantage in good 1 , and preferences are well behaved.
} 
such that the share of foreign firms in either industry is also constant. Points below this locus are such that the share of foreign firms in industry 1 is increasing since there is little international competition in this industry. Since the home country has comparative advantage in good 1 , the $L^{\mathrm{h}}$ locus is everywhere above $L^{\mathrm{f}}$; a firm in the home country can tolerate a higher fraction of foreign firms in industry one and still break even.

Fig. 1 underscores two crucial features of the general matching model. First, while the upper left corner is an absorbing state, it is not stable. Only absorbing states on the lower or right edge of the state space are. Since the parameters have been chosen to correspond to complete specialization, the lower right corner in Fig. 1 is the unique evolutionary equilibrium in this general matching model. Of course, if the parameters allowed for incomplete specialization, then there would be an absorbing state on the lower edge or on the right edge of the state space ${ }^{13}$. Second, the transitional dynamics need not be monotone. Indeed, it is possible to have initial conditions such that the share of firms in an industry is first increasing and then decreasing as the system adjusts to its long-run equilibrium.

\section{A restricted matching model}

In this section we analyze a slightly different model in which only international matches occur. Such a model might make sense if there were an equal number of home and foreign firms and if one thought of international trade as a special kind of matching process that assured that pairs of firms from two different countries meet in a special location, perhaps called "an international trading post".

Assumption 4. Every match is between a domestic and a foreign firm.

Agents still have identical preferences represented by a Cobb-Douglas utility function. Also, we continue to assume without loss of generality that the home country has comparative advantage in the first good. Still, there is one technicality about the production sets that the international economist must address. Until now, the population share determines a country's size. In a Ricardian model size matters, so we would be remiss if we forced the countries to be of equal size just to accommodate our restricted matching mechanism. Hence we will continue to assume that the production set of a home firm is the doubleton $Y=\left\{\left(1 / a_{1}, 0\right)^{\mathrm{T}},(0\right.$, $\left.\left.1 / a_{2}\right)^{\mathrm{T}}\right\}$, but we will modify the production set of the foreign firm to be

\footnotetext{
${ }^{13}$ With these production and taste parameters, if $\mu<0.38$ then the foreign country is large, and if $\mu>0.58$ then the home country is large. If the foreign country is large, both loci intersect the right edge of the state space, and the equilibrium occurs at the bottom right point of $L^{\mathrm{f}}$ since the marginal foreign firm is indifferent between the two activities. Analogous statements are true when the home country is large and the equilibrium is on the bottom edge of the state space at the bottom right point of $L^{\mathrm{h}}$.
} 
$Y^{*}=\left\{\left(L^{*} / a_{1}^{*}, 0\right)^{\mathrm{T}},\left(0, L^{*} / a_{2}^{*}\right)^{\mathrm{T}}\right\}$. Each home firm still has one unit of labor, but foreign firms are endowed with $L^{*}$ units.

Let $\tilde{\tilde{u}}=\left(1 / a_{1}\right)^{\alpha}\left(L^{*} / a_{2}^{*}\right)^{1-\alpha}$ and $\tilde{u}=\left(L^{*} / a_{1}^{*}\right)^{\alpha}\left(1 / a_{2}\right)^{1-\alpha}$. We again assume that $\tilde{\tilde{u}}>\tilde{u}$, and this condition is satisfied automatically if producing according to comparative advantage generates greater social surplus and the foreign country is not too large ${ }^{14}$. We can now summarize:

Assumption 5. The domestic (row player's) payoffs in an international match are

$$
\tilde{B}=\left[\begin{array}{cc}
0 & \tilde{\tilde{u}} \\
\tilde{u} & 0
\end{array}\right] .
$$

Also, $\tilde{\tilde{u}}>\tilde{u}$.

The domestic and foreign fitness functions are now $f(r, s)=r^{\mathrm{T}} \tilde{B} z^{*}$ and $f^{*}(r$, $s)=r^{\mathrm{T}} \tilde{B}^{\mathrm{T}} z$, respectively. Eqs. (2) and $(2 *)$ give the relevant fitness functions in this case.

$$
f(r, s)=r_{1} \tilde{\tilde{u}} z_{2}^{*}+r_{2} \tilde{u} z_{1}^{*}
$$

and

$$
f^{*}(r, s)=r_{1} \tilde{u} z_{2}+r_{2} \tilde{\tilde{u}} z_{1}
$$

Proposition 5.1. Impose Assumptions 4 and 5. Then there are two evolutionarily stable strategies, one with production according to comparative advantage and another with production according to comparative disadvantage.

Proof. See Appendix A.

The intuition is that the restricted matching process can lock firms into the wrong pattern of production because mutants will never meet anyone with whom to trade $^{15}$.

Now the replicator dynamics for domestic firms in industry $i$ are:

$$
\dot{z}_{i}=\left(e^{i}-z\right)^{\mathrm{T}}\left(\tilde{B} z^{*}\right) z_{i}
$$

and that for foreign firms is:

$$
\dot{z}_{i}^{*}=\left(e^{i}-z^{*}\right)^{\mathrm{T}}\left(\tilde{B}^{\mathrm{T}} z\right) z_{i}^{*} .
$$

\footnotetext{
${ }^{14}$ The exact condition is $\ln (\bar{u} / \bar{u})>(2 \alpha-1) \ln L^{*}$. Thus Assumption 5 is a bit more stringent than Assumption 3 since it puts a restriction on the size of the foreign country.

${ }^{15}$ An anonymous referee made the interesting observation that even the "wrong" assignment in this version of the model may well represent an increase in the average utility of both countries. These gains from trade are "non-Ricardian", and exist because trade leads to a greater division of labor within in each country so that in the evolutionarily stable state all sterile matches are eliminated.
} 
In this case, the state space $S=\Delta \times \Delta$ can be divided into four quadrants. The unstable Nash equilibrium has $\hat{z}_{1}=\tilde{u} /(\tilde{\tilde{u}}+\tilde{u})$ and $\hat{z}_{1}^{*}=\tilde{\tilde{u}} /(\tilde{\tilde{u}}+\tilde{u})$. If $z_{1}^{*}>\hat{z}_{1}^{*}$, then $\dot{z}_{1}<0$ and the home country is being pushed away from producing according to comparative advantage. Likewise, if $z_{1}<\hat{z}_{1}$, then $\dot{z}_{1}^{*}>0$ and the foreign country is also being pushed in the "wrong" direction. How likely is it that the world economy will get stuck in the "wrong" equilibrium? A natural starting point for the bimorphic population is $s(0)=\left((1 / 2,1 / 2)^{\mathrm{T}},(1 / 2,1 / 2)^{\mathrm{T}}\right)$, when two closed economies in long-run equilibrium open for international trade. The world economy will exhibit monotonic convergence to the equilibrium with comparative advantage if $\hat{z}_{1}<1 / 2<\hat{z}_{1}^{*}$. Since production according to comparative advantage generates greater social surplus, this chain of strict inequalities is true.

For an economist, it might be surprising that the equilibrium with comparative disadvantage is evolutionarily stable. Still, the essence of international trade is that there is an inherent difference between a domestic and a foreign firm. In a biological model, this fact connotes an ineluctable element of asymmetry, and the analysis of asymmetric conflicts is an ongoing area of research in evolutionary theory. Building on Maynard Smith and Parker (1976) and Maynard Smith (1982) himself coined the term the "Bourgeois Principle" in analyzing the bimorphic generalization of the Hawk-Dove game. Consider a situation in which a homeowner meets an intruder; Maynard Smith and Parker argue that the equilibrium in which the owner fights if the intruder flees and the intruder flees if the owner fights is the only "natural" evolutionarily stable strategy ${ }^{16}$. This is the Bourgeois principle, and it corresponds to the idea that the natural asymmetries arising in international trade will ensure that the equilibrium with comparative advantage will be selected.

This line of reasoning may be faulty in an economic environment. In a model with restricted bilateral matching, there is no guarantee that a sufficiently entrenched pattern of production will be displaced by foreign competition. Grafen (1987) first made this point in a biological model; in an owner-intruder conflict, the intruder has nothing to lose if fleeing confers no genetic advantage. Thus he may well fight, and Grafen calls this phenomenon the "Desperado effect". In the model in this section, the equilibrium where both countries produce according to comparative disadvantage has this flavor. There are myriad examples in economic geography where the location of industry is determined largely by historical happenstance, and political considerations often maintain a seemingly inefficient pattern of international production. Using a model with exogenous probabilities of death, Eshel and Sansone (1995) show that that there are sound theoretical reasons for either equilibrium to arise in bimorphic populations in the Hawk-Dove game.

\footnotetext{
${ }^{16}$ Davies (1978) describes the behavior of the speckled wood butterfly and shows that the "owner" of a sunny spot on the forest floor almost always wins conflicts with an otherwise identical intruder. Still, Maynard Smith (1982) (p. 96) describes the unusual case of the social spider Oecibus civitas that apparently abandons a refuge hole if challenged by an intruder.
} 
More recently, Binmore and Samuelson (2001) show that in asymmetric games with perturbed payoffs, approximations of mixed equilibria can be evolutionarily stable, thus blurring the sharp distinction between symmetric and asymmetric games.

\section{Stochastic dynamics in the open economy}

In this section, we will apply Foster and Young's (1990) techniques to analyze the stochastically stable equilibrium in the open economy. The analysis in Section 5 is a slight disappointment because there are initial conditions such that the world economy will eventually become polarized according to comparative disadvantage. If the initial distribution of firms in one country is biased towards the wrong sector, then it can force its trading partner to produce the wrong good in turn, and this downward spiral of comparative disadvantage reinforces itself. The crux of the problem is that one country is locked into the wrong technique at an early stage of international trade.

Of course, the evolution of the population of firms in a country is not really a deterministic system. Firms in senescent industries might be kept alive in part by rent seeking, and firms in growing industries may not immediately prosper because of idiosyncratic constraints in the labor or credit market. Also, an adverse terms-of-trade shock will simultaneously protect inefficient import-competing firms while making it more difficult for firms in a nascent exporting industry to prosper. Thus it is quite appropriate to posit a more general stochastic rule for the evolution of the populations of firms that allows small random effects to influence firms' survival rates. Following Foster and Young (1990), we now assume that the evolution of the share of domestic firms in the $i$-th industry is well approximated by a Wiener process:

$$
\mathrm{d} z_{i}=\left[e^{i}-z\right]^{\mathrm{T}}\left[\left(\mu A z+(1-\mu) B z^{*}\right) \mathrm{d} t+\sigma \Gamma(z) \mathrm{d} W\right] z_{i}
$$

where $\Gamma(z)$ is a $2 \times 2$ matrix continuous in $z$ and satisfying the property that $z^{\mathrm{T}} \Gamma(z)=(0,0)$, and $W$ is an $2 \times 1$ continuous white-noise process with mean zero and unit variance covariance matrix. We have suppressed the dependence of $z(t)$, $z^{*}(t)$, and $W(t)$ in this expression for ease of exposition. Likewise, the evolution of foreign firms is governed by:

$$
\mathrm{d} z_{i}^{*}=\left[e^{i}-z^{*}\right]^{\mathrm{T}}\left[\left(\mu B^{\mathrm{T}} z+(1-\mu) A^{*} z^{*}\right) \mathrm{d} t+\sigma^{*} \Gamma^{*}\left(z^{*}\right) \mathrm{d} W^{*}\right] z_{i}^{*}
$$

where all the terms are analogous. We assume that the stochastic processes $W(t)$ and $W^{*}(t)$ are independent; in essence, we are imposing that the idiosyncratic mutations that affect domestic firms do not spill across the border. Population 
distributions on the corners of the state space are absorbing. Thus it is natural examine its interior. We fix $\delta>0$ and consider the restricted state space $S_{\delta}=[\delta$, $1-\delta] \times[\delta, 1-\delta]$. If the share of type- 1 firms in a country becomes too small, then the state $\delta>0$ is a reflecting barrier; the analogous statement holds for $1-\delta$ if the share becomes too large.

Fig. 2 shows the simulation for the base case with general matching ${ }^{17}$. The annual mutation rate is $5 \%$, and the figure displays 500 years of monthly data. The production parameters were chosen so that the home country had comparative advantage in the first good, the taste parameter was set so that equal shares of income would be spent on either good, and the countries had equal populations. This figure is essentially the time series representation of the stochastic version of the phase diagram given in Fig. 1. The initial conditions for the world economy were set to mimic two closed economies in long-run equilibrium that open for trade.

The qualitative features of this figure are robust. Although there is a substantial variance in the shares of firms in each sector, the world economy converges rapidly to production according to comparative advantage. Shocks in the home country that decrease the share of firms in the natural exporting industry are propagated across borders and raise the share of foreign firms producing according to comparative disadvantage. This is made manifest by the negative correlation between the time series at the top of the figure and that on the bottom. There is no tendency for the pattern of trade to reverse in the long run because the equilibrium with comparative advantage is the basin with minimum potential. We also ran many simulations (not shown here) of the model with restricted matching using the

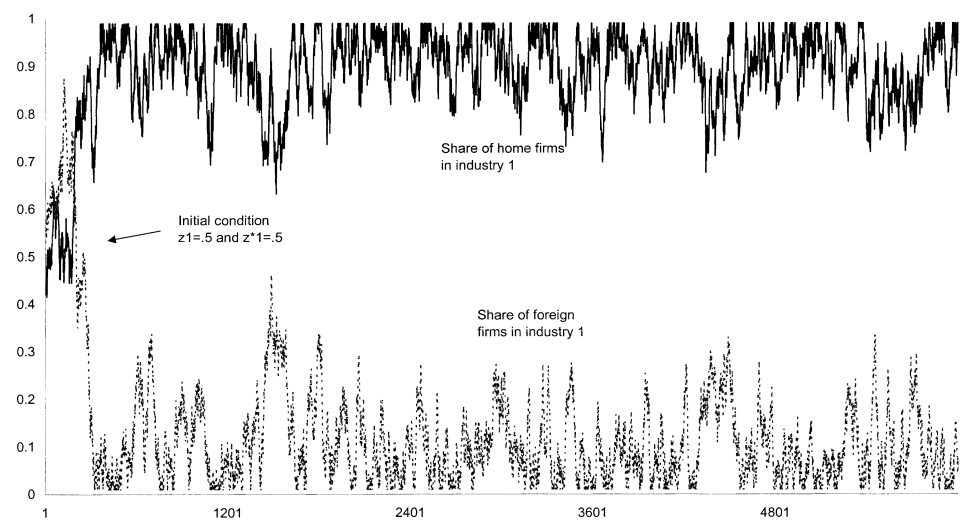

Fig. 2. General matching, 500 years of monthly data (annual standard deviation of $5 \%$ ).

\footnotetext{
${ }^{17}$ The production and taste parameters are the same as before. The foreign country has relative size $\mathcal{F}^{*} 1 \overline{7}_{z_{1}} 1, \sigma=0,05$ is the annual mutation rate, and $\delta=0.01$ is the reflecting barrier. We set $\Gamma(z)=$ $\left[\begin{array}{ll}1 / z_{1} & \\ -1 / z_{2} & -1 / z_{2}\end{array}\right]$ and $\Gamma^{*}(\cdot)=\Gamma(\cdot)$
} 
same parameters and initial conditions ${ }^{18}$. Again, there is rapid convergence to production according to comparative advantage. The main difference between this case and the general one is that the variance of the shares of firms between sectors is lower because in the model with restricted matching firms' decisions are strongly reinforcing across national boundaries.

How quickly will a pattern of trade according to comparative advantage arise? We ran repeated simulations of the general matching model starting from a situation in which the initial conditions were severely skewed against comparative advantage, with only $10 \%$ of the home firms in the "right" sector and $90 \%$ of the foreign firms in the "wrong" sector. Thus initial domestic firms in the natural exporting industry faced very severe "foreign competition," and there was great inertia in both countries keeping the pattern of trade in the wrong configuration. The median number of years during which domestic firms in the first industry were not predominant on the world stage was 54 , and the corresponding average was 76.5. Since mutations can - and occasionally do-cause the "right" trade pattern to go awry, these statistics are upper bounds for the typical waiting time for the world economy to set itself straight. Thus for these parameter values and extreme initial conditions, there was fairly rapid convergence to trade according to comparative advantage.

Fig. 3 shows what can happen if the world economy starts out in an unfavorable state and there is restricted matching. Again, the initial conditions are such that only $10 \%$ of firms in either country are in the "right sector". Now, it takes four centuries for the world economy to reach the equilibrium with comparative advantage, but when the change occurs, it is abrupt. Thus, if the initial conditions

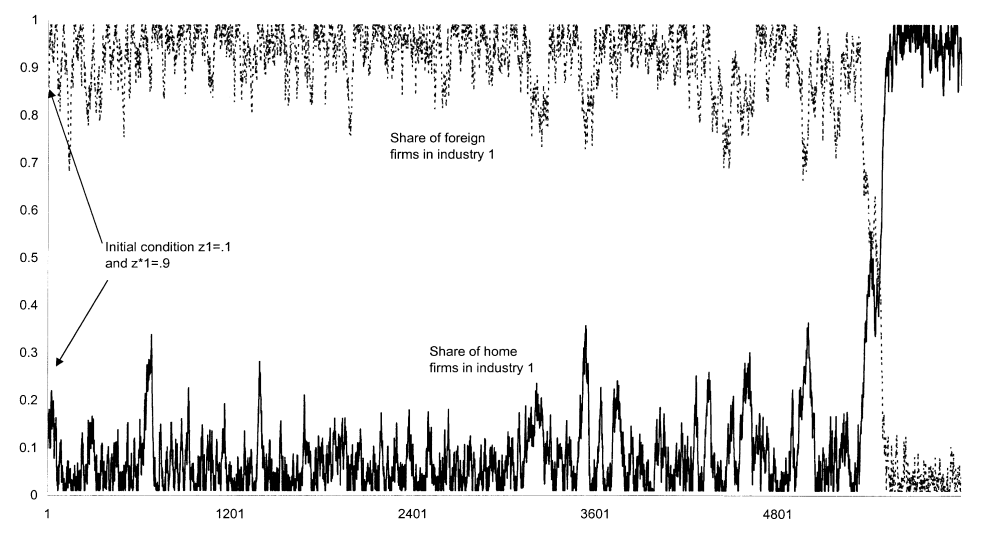

Fig. 3. Restricted matching, 500 years of monthly data (annual standard deviation of 5\%).

\footnotetext{
${ }^{18}$ Of course, we change the Wiener process to $d z_{i}=\left[e^{i}-z\right]^{\mathrm{T}}\left[\tilde{B} z^{*} d t+\sigma \Gamma(z) d W\right] z_{i}$ with $d z_{i}^{*}$ changed analogously. These values imply that $\hat{z}_{1} \approx 0.31$ and $\hat{z}_{1}^{*} \approx 0.69$.
} 
in the world economy entail the wrong pattern of specialization, the dynamic path of world trade has the flavor of Eldrige and Gould's (Eldrige and Gould, 1972) notion of a "punctuated equilibrium" in a biological system.

Since the standard deviation of the annual shocks is $5 \%$ and the reflecting barrier is $1 \%$, the share of home firms in the first industry is almost always between 1 and $10 \%$ in the initial phase of the world economy. Likewise, the share of foreign firms in that industry - the wrong one for them-is most often between 90 and $99 \%$ in this phase. The lower reflecting barrier insures that firms are born whenever the first sector in the domestic economy is in danger of dying out. Still, even if the mutation rate of firms is $5 \%$ per year, the pattern of trade is locked into the wrong equilibrium for a long time.

\section{Conclusion}

This paper has applied a new technique to one of the oldest questions in international economics and has showed that there are very sound evolutionary foundations for the notion of comparative advantage. Our model was very simple, perhaps unduly so. But the two-good Ricardian model with Mill-Graham preferences has an illustrious history in the long progression of the field of international economics. And for us it has the added advantage that the unique evolutionarily stable outcome in the closed economy maximizes expected social surplus, given the inefficiencies inherent in the matching process. An obvious area for future research is to study a model with more general preferences and arbitrarily many goods. We conjecture that production according to the chain of comparative advantage is in the stochastically stable set for a wide class of preferences and matching models.

There is a vein of literature in international trade on vent-for-surplus models ${ }^{19}$. Borrowing this term from Williams (1929) and Myint (1958) emphasizes that this way of thinking about international trade actually goes back to a key passage in the Wealth of Nations (fifth ed., 1789):

Between whatever places foreign trade is carried on, they all of them derive two distinct benefits from it. It carries out that surplus part of the produce of their land and labor for which there is no demand, and brings back in return for it something else for which there is a demand. It gives a value to their superfluities.... By means of it, the narrowness of the home market does not hinder the division of labor in any particular branch of art or

\footnotetext{
${ }^{19}$ This paragraph was inspired by the comments of an anonymous referee. A seminal paper by Caves (1965) helped bring these ideas to an influential audience of modern trade theorists.
} 
manufacture from being carried to the highest perfection ... (Vol. I, Cannan ed., p. 413$)^{20}$.

Myint's analysis is based on this insight, and his work can be seen broadly as a way of describing the costs and benefits of international trade in situations where the traditional model of comparative costs may not be germane. A matching model introduces an ineluctable element of distributive inefficiency into a model of international trade. It is noteworthy that the version of our model with restricted matching is able to capture the gains from trade due solely to increased division of labor, even when it is not aligned with comparative advantage. In that version, one of the evolutionary equilibria entails the "wrong" specialization. Still, both home and foreign agents may well be better off with trade because in the closed economy specialization is incomplete and half the matches are sterile. By contrast, international trade increases the division of labor in the world economy, and eliminates these sterile matches, thereby leading to potentially higher welfare. That is, trade enhances economic welfare by increasing the division of labor and enabling countries to overcome technical indivisibilities in production through a larger market size.

Our model is a detailed analysis of trade between countries facing severe trading frictions, and the strength of our conclusions probably lies in the fact that comparative advantage predicts trade even in this distorted economy. Perhaps our most important insight is that trade according to comparative advantage has a kind of stability that has never been known before. Why, exactly, is that kind of trade evolutionarily stable? We conjecture that comparative advantage is such a deep property of models of productive activity that it survives many market imperfections. Thus any oligopoly model that predicts trade against the pattern of comparative advantage must have made very severe and likely fragile assumptions about production or market structure. Evolutionary models are of course a very simple kind of imperfect competition, and we hope our work spurs further research in trade theory in this promising area.

What are some compelling extensions of our analysis? Studying a model with several countries poses a more daunting technical challenge for the applied theorist. The exact predictions of any such model will depend upon how one divides the gains from trade when several firms meet. Likewise, the dynamics of the world economy will be determined by the interaction between several populations of firms. Perhaps production according to comparative advantage will still occur, although it is also likely that the dynamics of the pattern of trade will be very complicated indeed. This is an open area of research for international economics or applied game theory.

\footnotetext{
${ }^{20}$ The entire text of Cannan's version (1904) of the fifth edition of the Wealth of Nations (1789) can be found at http://www.econlib.org/library/Smith/smWN.html.
} 
Our work shows how important the exact structure of the matching process is for a model of international trade. In the general matching model, production to according to comparative advantage arose in a model in which we had to make none of the many assumptions inherent in the usual neo-classical framework. In particular, there was no assumption about rational behavior, profit maximization, or common knowledge. Although our general matching model with random mutations showed a fairly wide variance in the distribution of firms between sectors in a plausible simulation, convergence to comparative advantage following trade liberalization was fairly rapid. In the model with restricted matching, production according to comparative disadvantage could occur, although this pattern was not in the stochastically stable set. These results stress the importance of stimulating domestic trade simultaneously with international trade liberalization in order to ensure specialization according to comparative advantage. The central implication of this work is that a general model of matching or random mutations in a restricted model of matching helps guarantee production according to comparative advantage, even in a model with myopic agents and trading frictions. We take this as a strong vindication of the insights of Ricardo.

\section{Uncited references}

Ricardo, 1963; Smith, 1776.

\section{Acknowledgements}

The work described in this paper was fully supported by a grant from the Research Grants Council of the Hong Kong Special Administrative Region, China [Project no. CityU 1148/99H]. The authors thank Co-editor Robert Staiger, two anonymous referees, James Bergin, Rick Bond, Jonathan Eaton, Ronald Jones, Larry Samuelson and seminar participants at The Ohio State University, City University of Hong Kong, Rutgers University's Conference on Research in International Trade, the University of Arkansas, the University of Pittsburgh, the Society for Economic Dynamics, the First World Congress of Game Theory, the Midwest International Economics Meetings, the International Economics and Finance Society, the University of Santa Cruz's New Methods in International Economics Workshop, and the City University of Hong Kong's International Conference on Recent Advances in International Economics for comments on earlier drafts.

\section{Appendix A}

Proposition 4.1. Complete specialization according to comparative disadvantage is not an equilibrium. 
Proof. Assume to the contrary that $s=\left(z, z^{*}\right)=\left((0,1)^{\mathrm{T}},(1,0)^{\mathrm{T}}\right)$ is an equilibrium. The fitness of a domestic firm is $f(r, s)=\mu u_{\mathrm{h}} r_{1}+(1-\mu) \bar{u} r_{2}$. Since $s$ is a Nash equilibrium, producing the first good cannot yield higher fitness and thus $\mu u_{\mathrm{h}} \leq$ $(1-\mu) \bar{u}$. Likewise, the fitness of a foreign firm is $f^{*}(r, s)=\mu \bar{u} r_{1}+(1-\mu) u_{\mathrm{f}} r_{2}$. Since $s$ is a Nash equilibrium, producing the second good cannot yield higher fitness and hence $\mu \bar{u} \geq(1-\mu) u_{\mathrm{f}}$. These two inequalities imply that $u_{\mathrm{h}} u_{\mathrm{f}} \leq \bar{u}^{2}$. But $0<u_{\mathrm{h}} u_{\mathrm{f}}=\bar{u} \bar{u}$. Hence $\bar{u} \leq \bar{u}$, contradicting the assumption that $\bar{u}>\bar{u}$.

Proposition 4.2. No Nash equilibrium is such that a country is completely specialized in the good in which it has a comparative disadvantage.

Proof. Assume first that the home country is incompletely specialized and $s=(z$, $\left.z^{*}\right)=\left(\left(z_{1}, z_{2}\right)^{\mathrm{T}},(1,0)^{\mathrm{T}}\right)$ is a Nash equilibrium. Since a domestic firm finds it equally profitable to produce either good, $\mu z_{2} u_{\mathrm{h}}=\mu z_{1} u_{\mathrm{h}}+(1-\mu) \bar{u}$ and thus $\mu\left(z_{2}-z_{1}\right) u_{\mathrm{h}}=(1-\mu) \bar{u}$. Since this is an equilibrium, it must not be the case that a foreign firm finds it more profitable to produce the second good. Hence, $\mu z_{2} \bar{u} \geq$ $\mu \mathrm{z}_{1} \bar{u}+(1-\mu) u_{\mathrm{f}}$. But this inequality implies that $\mu\left(z_{2}-z_{1}\right) \bar{u}>(1-\mu) u_{\mathrm{f}}$, where the strict inequality follows from $\bar{u}>\bar{u}$. Dividing this strict inequality by the analogous equality yields $\bar{u} / u_{\mathrm{h}}>u_{\mathrm{f}} / \bar{u}$, which is equivalent to $\bar{u} \bar{u}>u_{\mathrm{h}} u_{\mathrm{f}}$. But this is a contradiction because $\bar{u} \bar{u}>u_{\mathrm{h}} u_{\mathrm{f}}$.

Assume next that the foreign country is incompletely specialized and thus $s=(z$, $\left.z^{*}\right)=\left((0,1)^{\mathrm{T}},\left(z_{1}^{*}, z_{2}^{*}\right)^{\mathrm{T}}\right)$ is a Nash equilibrium. Since a foreign firm finds it equally profitable to produce either good, $(1-\mu) z_{1}^{*} u_{\mathrm{f}}=\mu \bar{u}+(1-\mu) z_{2}^{*} u_{\mathrm{f}}$ and thus $(1-$ $\mu)\left(z_{1}^{*}-z_{2}^{*}\right) u_{\mathrm{f}}=\mu \bar{u}$. Since this is an equilibrium, a home firm cannot find it more profitable to produce the first good and thus $(1-\mu) z_{1}^{*} \bar{u} \geq \mu u_{\mathrm{h}}+(1-\mu) z_{2}^{*} \bar{u}$. This weak inequality implies that $(1-\mu)\left(z_{1}^{*}-z_{2}^{*}\right) \bar{u}>\mu u_{\mathrm{h}}$, where again we have used the fact that $\bar{u}>\bar{u}$. Thus we may derive $\bar{u} / u_{\mathrm{f}}>u_{\mathrm{h}} / \bar{u}$, again a contradiction of the fact that $\bar{u} \bar{u}=u_{\mathrm{h}} u_{\mathrm{f}}$.

Proposition 4.4. There is no Nash equilibrium in which both countries are incompletely specialized.

Proof. Assume that both countries are incompletely specialized and that $s=(z$, $\left.z^{*}\right)=\left(\left(z_{1}, z_{2}\right)^{\mathrm{T}},\left(z_{1}^{*}, z_{2}^{*}\right)^{\mathrm{T}}\right)$ is an equilibrium. Since a domestic firm finds it equally profitable to produce either good, $\mu z_{2} u_{\mathrm{h}}+(1-\mu) z_{2}^{*} \bar{u}=\mu z_{1} u_{\mathrm{h}}+(1-\mu) z_{1}^{*} \bar{u}$. Likewise, a foreign firm finds it equally profitable to produce either good and $\mu z_{2} \bar{u}+(1-\mu) z_{2}^{*} u_{\mathrm{f}}=\mu z_{1} \bar{u}+(1-\mu) z_{1}^{*} u_{\mathrm{f}}$. Since $z_{2}=1-z_{1}$ and $z_{2}^{*}=1-z_{1}^{*}$, the first equality implies $\mu\left(1-2 z_{1}\right) u_{\mathrm{h}}=(1-\mu)\left(z_{1}^{*}(\bar{u}+\underline{u})-\bar{u}\right)$ and the second implies $\mu\left(\underline{u}-z_{1}(\bar{u}+\underline{u})\right)=(1-\mu)\left(2 z_{1}^{*}-1\right) u_{\mathrm{f}}$. Solving the first equation for $z_{1}^{*}$ yields

$$
z_{1}^{*}=\frac{\mu u_{\mathrm{h}}+(1-\mu) \bar{u}}{(1-\mu)(\bar{u}+\bar{u})}-\frac{2 \mu u_{\mathrm{h}}}{(1-\mu)(\bar{u}+\bar{u})} z_{1} .
$$


Likewise, solving the second equation for $z_{1}^{*}$ yields gives

$$
z_{1}^{*}=\frac{\mu \bar{u}+(1-\mu) u_{\mathrm{f}}}{2(1-\mu) u_{\mathrm{f}}}-\frac{\mu(\bar{u}+\bar{u})}{2(1-\mu) u_{\mathrm{f}}} z_{1} .
$$

We will now show in two steps that this system of two equations does not have a solution such that $0 \leq z_{1}^{*} \leq 1$. First, we will show that the intercept of the first line is strictly greater than that of the second line. Second, we will show that the slope of the first line is strictly greater than that of the second. We establish the first step if $\left(\mu u_{\mathrm{h}}+(1-\mu) \bar{u}\right) /(\bar{u}+\bar{u})>\left(\mu \bar{u}+(1-\mu) u_{\mathrm{f}}\right) / 2 u_{\mathrm{f}}$. Cross-multiplying yields the following logically equivalent inequalities

$$
\begin{aligned}
2 u_{\mathrm{f}}\left(\mu u_{\mathrm{f}}+(1-\mu) \bar{u}\right) & >\left(\mu \bar{u}+(1-\mu) u_{\mathrm{f}}\right)(\bar{u}+\bar{u}) \Leftrightarrow 2 \mu \bar{u} \bar{u}+2(1-\mu) \bar{u} u_{\mathrm{f}} \\
& >\left(\mu \bar{u}+(1-\mu) u_{\mathrm{f}}\right)(\bar{u}+\bar{u}) \Leftrightarrow 2 \mu \bar{u} \bar{u}+2(1-\mu) \bar{u} u_{\mathrm{f}} \\
& >\mu \bar{u} \bar{u}+\mu(\bar{u})^{2}+(1-\mu) u_{\mathrm{f}} \bar{u}+(1-\mu) \bar{u} u_{\mathrm{f}} \Leftrightarrow \mu \bar{u} \bar{u} \\
& +(1-\mu) \bar{u} u_{\mathrm{f}}>\mu(\bar{u})^{2}+(1-\mu) \bar{u} u_{\mathrm{f}} \Leftrightarrow \mu\left(\bar{u} \bar{u}-(\bar{u})^{2}\right) \\
& >(1-\mu)(\bar{u}-\bar{u}) u_{\mathrm{f}} \Leftrightarrow \mu \bar{u}(\bar{u}-\bar{u}) \\
& >(1-\mu)(\bar{u}-\bar{u}) u_{\mathrm{f}} \Leftrightarrow \mu \bar{u}>-(1-\mu) u_{\mathrm{f}}
\end{aligned}
$$

where we have again used the fact that $u_{\mathrm{f}} u_{\mathrm{h}}=\bar{u} \bar{u}$. We now establish the second step. We must show that $-\left(2 \mu u_{\mathrm{h}}\right) /(1-\mu)(\bar{u}+\bar{u})>-(\mu(\bar{u}+\bar{u})) / 2(1-\mu) u_{\mathrm{f}}$. This inequality is logically equivalent to this chain:

$$
\begin{aligned}
\frac{2 \mu u_{\mathrm{h}}}{(1-\mu)(\bar{u}+\bar{u})} & <\frac{\mu(\bar{u}+\bar{u})}{2(1-\mu) u_{\mathrm{f}}} \Leftrightarrow 4 u_{\mathrm{h}} u_{\mathrm{f}}<(\bar{u}+\bar{u})^{2} \Leftrightarrow 4 \bar{u} \bar{u}<(\bar{u}+\bar{u})^{2} \Leftrightarrow 0 \\
& <(\bar{u}-\bar{u})^{2}
\end{aligned}
$$

where we have again used that $u_{\mathrm{f}} u_{\mathrm{h}}=\bar{u} \bar{u}$.

Proposition 4.5. The pattern of production according to comparative advantage is evolutionarily stable.

Proof. Since this is a game with two players each having finitely many pure strategies, it has an equilibrium. Proposition 4.4 shows that the equilibrium cannot have both players mixing simultaneously. Also, Proposition 4.2 implies that a country is completely specialized only if it is producing according to comparative advantage.

Consider first a Nash equilibrium in which the home firms are completely specialized and thus $s=\left(z, z^{*}\right)=\left((1,0)^{\mathrm{T}},\left(z_{1}^{*}, z_{2}^{*}\right)^{\mathrm{T}}\right)$. Since domestic firms produce only the first good, $(1-\mu) z_{2}^{*} \bar{u} \geq \mu u_{\mathrm{h}}+(1-\mu) \bar{u} z_{1}^{*}$. Let $\varepsilon>0$ be sufficiently small, 
and consider a mutation by a share $\varepsilon$ of domestic firms where these firms produce only the second good. The fitness of the (domestic) mutants is $f\left(r, s_{\varepsilon}\right)=\mu(1-$ $\varepsilon) u_{\mathrm{h}}+(1-\mu) z_{1}^{*} \bar{u}$, and the fitness of the rest of the domestic firms is $f(z$, $\left.s_{\varepsilon}\right)=\mu \varepsilon u_{\mathrm{h}}+(1-\mu) z_{2}^{*} \bar{u}$. Since $\varepsilon>0$, the weak inequality implies that $f\left(r, s_{\varepsilon}\right)<f(z$, $s_{\varepsilon}$ ) and thus specializing in the first good is evolutionarily stable.

Consider next a Nash equilibrium in which the domestic firms are incompletely specialized and the foreign firms are completely specialized. Now $s=\left(z, z^{*}\right)=\left(\left(z_{1}\right.\right.$, $\left.\left.z_{2}\right)^{\mathrm{T}},(0,1)^{\mathrm{T}}\right)$. Since domestic firms are indifferent between producing either good, $\mu z_{2} u_{\mathrm{h}}+(1-\mu) \bar{u}=\mu z_{1} u_{\mathrm{h}}$. Again, consider a mutation by a sufficiently small share $\varepsilon>0$ of domestic firms that produce only the first good. (Producing the second good will obviously lower the mutants' fitness since they give up all matches according to comparative advantage with foreign firms.) The fitness of the domestic mutants is $f\left(r, s_{\varepsilon}\right)=\mu z_{2}(1-\varepsilon) u_{\mathrm{h}}+(1-\mu) \bar{u}$, and the fitness of the rest of the population of domestic firms is $f\left(z, s_{\varepsilon}\right)=z_{1}\left[\mu z_{2}(1-\varepsilon) u_{\mathrm{h}}+(1-\mu) \bar{u}\right]+$ $z_{2} \mu\left[z_{1}(1-\varepsilon)+\varepsilon\right] u_{\mathrm{h}}$. Hence, the difference $f\left(z, s_{\varepsilon}\right)-f\left(r, s_{\varepsilon}\right)=\left(z_{1}-1\right)\left[\mu z_{2}(1-\right.$ $\left.\varepsilon) u_{\mathrm{h}}+(1-\mu) \bar{u}\right]+z_{2} \mu\left[z_{1}(1-\varepsilon)+\varepsilon\right] u_{\mathrm{h}}$

$$
\begin{aligned}
& =\left(z_{1}-1\right)\left[\mu z_{2} u_{\mathrm{h}}+(1-\mu) \bar{u}-\varepsilon \mu z_{2} u_{\mathrm{h}}\right]+z_{2} \mu\left[z_{1}(1-\varepsilon)+\varepsilon\right] u_{\mathrm{h}} \\
& =\left(z_{1}-1\right)\left[\mu z_{1} u_{\mathrm{h}}-\varepsilon \mu z_{2} u_{\mathrm{h}}\right]+\left(1-z_{1}\right) \mu\left[z_{1}+\varepsilon\left(1-z_{1}\right)\right] u_{\mathrm{h}}
\end{aligned}
$$

(using $\mu z_{2} u_{\mathrm{h}}+(1-\mu) \bar{u}=\mu z_{1} u_{\mathrm{h}}$ and $z_{2}=1-z_{1}$ )

$$
\begin{aligned}
& =\mu u_{\mathrm{h}}\left(z_{1}-1\right)\left[z_{1}-\varepsilon z_{2}\right]+\left(1-z_{1}\right) \mu\left[z_{1}+\varepsilon\left(1-z_{1}\right)\right] u_{\mathrm{h}} \\
& =\mu u_{\mathrm{h}}\left(z_{1}-1\right)\left[(1+\varepsilon) z_{1}-\varepsilon-z_{1}-\varepsilon\left(1-z_{1}\right)\right]
\end{aligned}
$$

(using $z_{2}=1-z_{1}$ and factoring common terms)

$$
=2 \mu u_{\mathrm{h}} \varepsilon\left(z_{1}-1\right)^{2}>0 .
$$

Since the labels "home firm" and "good 1" were arbitrary, it is obvious that these arguments generalize to the relevant cases for the foreign firm.

Proposition 5.1. Impose Assumptions 4 and 5. Then there are two evolutionarily stable strategies, one with production according to comparative advantage and another with production according to comparative disadvantage.

Proof. There are three Nash equilibria: $\left((1,0)^{\mathrm{T}},(0,1)^{\mathrm{T}}\right),\left((0,1)^{\mathrm{T}},(1,0)^{\mathrm{T}}\right)$, and $\hat{s}=\left(\left(\hat{z}_{1}, \hat{z}_{2}\right)^{\mathrm{T}},\left(\hat{z}_{1}^{*}, \hat{z}_{2}^{*}\right)^{\mathrm{T}}\right)$, where $\hat{z}_{1}=\tilde{u} /(\tilde{\tilde{u}}+\tilde{u}), \hat{z}_{2}=\tilde{\tilde{u}} /(\tilde{\tilde{u}}+\tilde{u}), \hat{z}_{1}^{*}=\tilde{\tilde{u}} /(\tilde{\tilde{u}}+\tilde{u})$, and $\hat{z}_{2}^{*}=\tilde{u} /(\tilde{\tilde{u}}+\tilde{u})$. The first two are strict Nash equilibria and thus are evolutionarily stable strategies for this game with a bimorphic population.

Now consider the (mixed strategy) equilibrium $\hat{s}$. Since domestic firms never meet each other, a small share can deviate and produce the first good without lowering their average fitness as compared with the rest of the population of domestic firms. So this equilibrium is not evolutionarily stable. 


\section{References}

Alchian, A.A., 1950. Uncertainty, evolution, and economic theory. Journal of Political Economy 57, 211-221.

Binmore, K., Samuelson, L., 2001. Evolution and mixed strategies. Games and Economic Behavior 34, 200-226.

Caves, R.E., 1965. Vent for surplus models of trade and growth. In: Caves, R.E., Johnson, H.G., Kenen, P.B. (Eds.), Trade, Growth and the Balance of Payments: Essays in Honor of Gottfried Haberler. Rand McNally and Co, Chicago, pp. 95-155.

Cordella, T., Gabszewicz, J.J., 1997. Comparative advantage under oligopoly. Journal of International Economics 43, 333-346.

Davies, N.B., 1978. Territorial defence in the speckled wood butterfly (Pararge aegeria): the resident always wins. Animal Behaviour 26, 138-147.

Diamond, P.A., 1982. Aggregate demand management in search equilibrium. Journal of Political Economy 90, 881-894.

Eldrige, N., Gould, S.J., 1972. Punctuated equilibrium: an alternative to phyletic gradualism. In: Schopf, T.J.M. (Ed.), Models in Paleobiology. Freeman, Cooper and Co, San Francisco, pp. 82-115.

Eshel, I., Sansone, E., 1995. Owner-intruder conflict, Grafen effect, and self-assessment. The Bourgeois principle re-examined. Journal of Theoretical Biology 177, 341-356.

Fisher, E.O’N., 1985. Three Essays in International Trade Theory under Imperfect Competition. Doctoral Dissertation, University of California at Berkeley.

Foster, D., Young, P., 1990. Stochastic evolutionary game dynamics. Theoretical Population Biology 38, 219-232.

Friedman, D., 1991. Evolutionary games in economics. Econometrica 59, 637-666.

Friedman, D., 1998. On economic applications of evolutionary game theory. Journal of Evolutionary Economics 8, 15-43.

Friedman, D., Fung, K.C., 1996. International trade and the internal organization of the firm: an evolutionary approach. Journal of International Economics 43, 113-137.

Gabszewicz, J.J., Vial, J.P., 1972. Oligopoly à la Cournot in general equilibrium analysis. Journal of Economic Theory 4, 381-400.

Golub, S.S., Hsieh, C.T., 2000. Classical Ricardian theory of comparative advantage revisited. Review of International Economics 8, 221-234.

Grafen, A., 1987. The logic of divisively asymmetric contests: respect for ownership and the Desperado effect. Animal Behaviour 35, 462-467.

Kiyotaki, N., Wright, R., 1989. On money as a medium of exchange. Journal of Political Economy 97, 927-954.

Maynard Smith, J., 1982. Evolution and the Theory of Games. Cambridge University Press, Cambridge.

Maynard Smith, J., Parker, G.A., 1976. The logic of asymmetric contests. Animal Behaviour 24, $159-175$.

Myint, H., 1958. The 'classical theory' of international trade and the underdeveloped countries. Economic Journal 68, 317-337.

Ricardo, D., 1963. The Principles of Political Economy and Taxation. Irwin, Homewood, IL.

Ruffin, R., 2001. Oligopoly and Trade: What, How Much, and for Whom? Unpublished manuscript, University of Houston.

Samuelson, L., 1997. Evolutionary Games and Equilibrium Selection. The MIT Press, Cambridge.

Selten, R., 1980. A note on evolutionarily stable strategies in asymmetric animal conflicts. Journal of Theoretical Biology 84, 93-101.

Skidelsky, R., 1992. John Maynard Keynes. The Economist as Saviour, 1920-1937, vol. 2. Macmillan London Limited. 
Smith, A., 1776. An Inquiry into the Nature and Causes of the Wealth of Nations, first ed. Edwin Cannan's Annotated Version of the Fifth Edition (1789). Methuen \& Co., Ltd., London, 1904. Vega-Redondo, F., 1996. Evolution, Games, and Economic Behavior. Oxford University Press. Vega-Redondo, F., 1997. The evolution of Walrasian behavior. Econometrica 65, 375-384. Weibull, J.W., 1995. Evolutionary Game Theory. The MIT Press, Cambridge.

Williams, J.H., 1929. The theory of international trade reconsidered. Economic Journal 39, 195-209. 